\title{
Research on the Relationship Between Job Competence and Job Well-Being in Service Industry-Based on the Mediating Effect of Job Insecurity
}

\author{
Yan-Hua Diao ${ }^{1,2}$, Chun-Shuo Chen ${ }^{3}$ \\ ${ }^{1}$ The China-ASEAN International College, Dhurakij Pundit University, Bangkok, Thailand \\ ${ }^{2}$ Shandong Youth University of Political Science, Jinan, Shandong, China \\ ${ }^{3}$ Dhurakij Pundit University, Bangkok, Thailand \\ Correspondence: Yan-Hua Diao, Shandong Youth University of Political Science, Shandong, China.
}

Received: October 16, 2019

Accepted: November 6, 2019

Online Published: November 14, 2019

doi:10.5539/ibr.v13n1p1

URL: https://doi.org/10.5539/ibr.v13n1p1

\begin{abstract}
This paper takes 328 questionnaires of supervisors and employees in the service industry as samples and verifies the mechanism of the relationship between job competence and job well-being from the perspective of mediating effect of job insecurity and moderating effect of perceived organizational support. The results show that job competence has a significant positive impact on job well-being, the stronger job competence is, and the higher job well-being will be. And the positive effect of job competence on job well-being is mediated by job insecurity. Job competence has a positive effect on job insecurity, job insecurity has a significant negative effect on job well-being, and perceived organizational support moderates the relationship between job insecurity and job well-being, with the increase of perceived organizational support, the negative influence of job insecurity on job well-being decreased. It provides new ideas for the service industry to strengthen care and support for employees to reduce job insecurity, improve employee happiness and motivate employees.
\end{abstract}

Keywords: job well-being, job competency, job insecurity, perceived organizational support

\section{Introduction}

With the rise of active organizational behavior theory and China's emphasis on modern service industry talents, the job well-being of service industry talents has gradually become a hot issue in research field. Active organizational behavior theory with the mission of pursuing employees healthy and happy (Meneghel, 2016), aims to benefit both organizations and employees and realize win-win. In modern service industry, the employees with combination of service, knowledge and skills often communicate with customers and provide service to customers face-to-face. Whether they feel satisfied and happy at work will directly affect their service behavior and service attitude. Ultimately, it affects the quality of service, which in turn affects customer's mood and purchasing behavior, and even affects customer satisfaction and loyalty, it can even affect the achievement of organizational goals. In current China, the occupational characteristics of modern service industry and the uncertainty of labor market have increased employees' sense of job insecurity, affected their personal physical and mental health and happiness, affected their organizational commitment, and led to resignation tendency. Therefore, perceived organizational support is valued by enterprise managers and scholars. The perceived organizational support can understand employees' needs and expectations for the organization from the perspective of employees, reduce their insecurities by satisfying their needs, and stimulate their attitudes and behaviors that are conducive to the organization.

Both theoretical and empirical studies have shown that job competency is an important factor affecting job well-being, but the mechanism is not clear. Existing research mainly focus on the influencing factors and evaluation model of job competency or job well-being alone. There are few studies research on the relationship between them and the influencing mechanism. This study takes the employees of China's modern service industry as the survey respondents, by introducing job insecurity and perceived organizational support as intermediate variables for empirical analysis, explores the relationship between job competency and job well-being through empirical analysis, and investigates the role of relevant variables of the psychological level in order to enriching theoretical research of job competence and job well-being. 


\section{Literature Review}

With regard to the definition of competency, the current authoritative definition is given by McClelland (1973). He believes that job competency refers to personal traits such as knowledge, attitude, values, and motivation. It can be expressed through work performance and can be measured by some specific methods. In this study, it is considered that job competency is an individual trait that can distinguish different job performance, which may be manifested as high cognitive ability, good values and excellent behavioral skills.

The initial study on job insecurity came from Greenhalgh and Rosenblatt (1984), who defined job insecurity as an employee's sense of inability to maintain the desired continuity in a threatened work situation. At present, scholars still disagree on the definition of job insecurity. This study believes that job insecurity refers to the sense of employees' inability to maintain their expectations in a threatened work situation. This sense of powerlessness is not only the fear of losing jobs, but also the fear of losing some job characteristics and resources (Greenhalgh\& Rosenblatt, 1984; Reichert, 2015; Witte, 2016).

Eisenberger (1986) based on the social exchange theory in social psychology, first proposed the concept of Perceived Organizational Support (POS), which is used to express employees' Perceived Organizational commitment to themselves. It is believed that the perceived organizational support refers to employees' perception and view on whether the organization cares about their interests and attaches importance to their contributions, and the questionnaire of perceived organizational support is developed, which is used for reference in this study.

The research results on happiness in China and abroad are extremely rich, and the connotation categories can be divided into two major research factions: subjective well-being and psychological well-being. This study believes that job well-being firstly displays subjective well-being and is also closely related to psychological well-being. It is the positive or negative emotion that the staff feels in the process of pursuing self-value realization.

\section{Methodology Design}

\subsection{Research Hypothesis}

A large number of empirical studies have found the relationship between job competency, job insecurity, perceived organizational support and job well-being. Cuyper (2014) studied the relationship between job competency and job well-being and the role of job insecurity as a madiator variable. Some scholars have studied the role of perceived organizational support as a moderator. For example, Kurtessis et al. (2015) believes that perceived organizational support can moderate the relationship between leader-member exchange (LMX) and job satisfaction of employee. Wen et al. (2018) found that perceived organizational support plays a moderating role in the relationship between emotional labor and job satisfaction Yeves et al. (2019) studied the moderating effect of perceived employability on job insecurity and job satisfaction.

Abraido-lanza(1997)proposed that personal ability plays an important role in the job well-being. Occupational competency can bring positive employee behaviors to the organization, such as improving employee's job satisfaction in the organization (Akkermans et al., 2013; Tomietto et al., 2019).It can be seen that job competency plays an important role in improving job well-being.

The relationship between job competency and job insecurity is controversial. Some scholars believe that job competency can help employees find jobs and cope with job insecurity (Fugate, 2004). Job competency can bring positive career development results to employees, such as reducing occupational insecurity (Kuijpers, 2006; Colakoglu, 2011). However, some scholars believe that employees with higher job competency are more likely to perceive job insecurity than those with lower job competency (Atkinson, 1984).

Most studies on the relationship between job insecurity and happiness by scholars have found that there is a negative correlation between them, and job insecurity will lead to lower happiness (Ferrie et al., 1998; Hellgren, 2010; Elst, 2014). Griep (2016) believes that job insecurity is harmful and detrimental to health and low satisfaction. Elst et al. (2011) found that job insecurity frustrated employees' psychological needs, and then negatively affected their happiness. Emberland et al. (2010) believed that job insecurity had a significant negative predictive effect on psychological well-being. Menendez et al. (2019) studied that job insecurity has a significant negative impact on job well-being of employees.

Studies on the perceived organizational support have found that there is a significant positive relationship between perceived organizational support and job satisfaction, and job satisfaction is an important factor of job well-being (Rhoades, 2002; Panaccio \& Vandenberghe, 2009); Perceived organizational support is closely related to job well-being, and good organizational support can help improve job well-being (Wang et al., 2018; 
Maria et al., 2019). Faris (2018) proposed that job insecurity is significantly positively correlated with resignation intention, and organizational support and commitment play a moderating role in the relationship between job insecurity and resignation intention.

Based on these research foundations, this study believes that job competency will have a positive impact on the job well-being of service industry employees, and job insecurity plays an important intermediary role in the relationship. Hereby, this study designed the research framework as shown in Figure 1 and proposed relevant hypotheses.

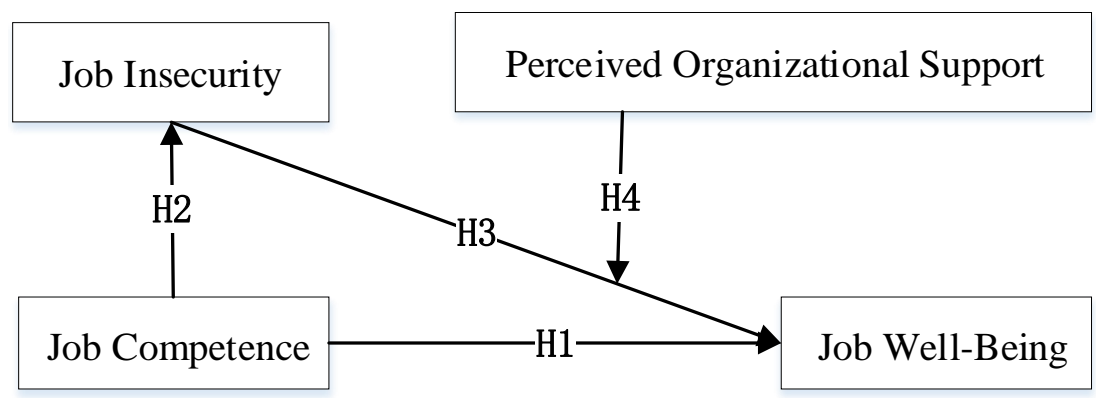

Figure 1. The research framework

In the theoretical model of this study, job competence is an independent variable, job well-being is a dependent variable, and job insecurity is a mediator variable, moderators such as perceived organizational support is also added in this research in order to discuss its effects on job competence and job well-being. Based on the above research framework, the following research hypotheses are proposed:

H1: The job competency has a significant positively effect on job well-being.

$\mathrm{H} 2$ : Job competence has a significant negative effect on job insecurity.

H3: Job insecurity has a significant negative effect on job well-being.

H4: Perceived organizational support moderates the relationship between job insecurity and job well-being. With the increase of perceived organizational support, the negatively influences of job insecurity on job well-being is smaller.

H5: Job insecurity mediates the relationship between job competence and job well-being.

\subsection{Research Tools}

In this study, the required data were collected by questionnaire survey, and the first draft of questionnaire was prepared with reference to relevant mature scales. First, the draft will be submitted to the relevant field experts to review and put forward Suggestions for revision. Then, the modified questionnaire was used to conduct the pre-test survey, and the reliability and validity of the questionnaire were evaluated with the pre-test survey data. Finally, the formal questionnaire was determined after optimization according to the evaluation results, and the investigation was carried out according to the formal questionnaire. The following is a detailed description of the compilation and content composition of the questionnaire.

The questionnaire is divided into five parts: personal background information, job competency scale, job insecurity scale, job well-being scale and perceived organizational support scale. The questions in the scale are based on the Likert five-point scoring type. From 1 to 5, they represent five levels of strongly disagreement, disagreement, generality, agreement, strongly agreement.

The job competency scale is based on the relevant foreign theories and the scale designed by Zhu (2014) on the job competence of service personnel, which has a total of 9 questions. The Job Insecurity Scale used the Hellgren et al. (1999) scale for a total of 6 questions which includes two dimensions about continuity and development. The Perceived Organizational Support Scale used the simplified version of Eisenberger (1986) scale for a total of 5 questions. The job well-being Scale draws on the PWB scale designed by Abbott et al. (2006) and is revised based on the actual survey. It is divided into six dimensions: self-acceptance, job value, benefits and income, development prospect, environment control and interpersonal relationship. There are 28 questions in total. 
In addition, in order to avoid the possible expansion or contraction of the concept caused by the variation of the common method, it would lead to the error of the subsequent hypothesis inference. In this study, the effects of CMV were prevented through questionnaire layout design and paired survey.

\subsection{Sampling Method and Sample Size Allocation}

The sample of this study comes from the service industry personnel. This study selects the individual employees of the communication, finance, tourism and education service enterprises with relatively large number of employees as the questionnaire survey object. In order to ensure the representativeness and operability of the sample, a sampling method combining staged stratified random sampling is adopted, and 300 people are taken as samples. In the first stage, the country is divided into the eastern, central and western regions as the three levels of sampling. In the second phase, five provinces are sampled by simple random sampling in each layer. The sample provinces are allocated according to the number of eastern, central and western provinces. There are two provinces in the east and west, and one province in the central part. The results are Shandong, Shaanxi, Jilin, Guangdong, and Yunnan respectively. In the third phase, service employees were randomly selected from the database of social security department of the sampled province, with an average of 75 employees from each of the four industries and 15 employees from each province in each industry.

In addition, in order to ensure the validity and accuracy of variable measurement, the research uses the paired research method, because the survey of job competency cannot only be based on the individual self-evaluation of the employees, but the supervisors should also evaluate the competence of the respondents, and then carry out the weighted conversion. So matching survey is needed. This is done by matching service employees to their supervisors, and asking them a questionnaire. The data obtained from the supervisor's survey and the survey data of the object of study are averaged to obtain the survey data of job competency.

In this study, Amos research and analysis software was used to verify the fitting degree of structural equation model. Structural equation model has high requirements, and it is not appropriate to require too large or too small sample size. Gorsuch (1983) believes that the ratio of sample size to the number of variables should be more than 5 to 1 , and the larger the better in principle Considering the number of variables, the sample size determined in this study is about 300 . Considering the inefficiency of about $15 \%, 350$ questionnaires were distributed in the formal survey.

\section{Empirical Results}

\subsection{Descriptive Statistical Analysis}

In the pre-survey, 50 questionnaires were distributed, 50 questionnaires were recovered, and 3 invalid questionnaires were eliminated. Through item analysis, reliability analysis and validity analysis of the pre-survey data, it was found that the scale had good reliability and validity. The questionnaire with small sample test was applied to the formal investigation.

A total of 350 questionnaires were actually distributed in this formal investigation, and 342 were recovered, with a recovery rate of $97.7 \%$. According to the matching survey design of the questionnaire, 318 people were responsible for the investigation, and 318 pairs of questionnaires were collected, covering the personal evaluation of 340 people. After sorting out, 328 effective questionnaires were obtained, with an effective rate of 93.7\%. Among the 328 respondents, the sample distribution is basically consistent with the overall distribution status of service industry employees.

As shown in table 1, this study involves a survey of four variables. As for the distribution of samples among all variables, the results show that the mean value is higher than 3.0, indicating that the respondents generally have a higher ability or level in these aspects.

Table 1. Descriptive statistics of each variable

\begin{tabular}{cccccc}
\hline Dimension & $\begin{array}{c}\text { Sample } \\
\text { size }\end{array}$ & Mean & Standard deviation & Minimum & Maximum \\
\hline Job Competence & 328 & 3.947 & 0.922 & 1 & 5 \\
Job Insecurity & 328 & 3.796 & 0.946 & 1 & 5 \\
Perceived Organizational Support & 328 & 3.572 & 0.972 & 1 & 5 \\
Job Well-being & 328 & 3.690 & 0.880 & 1 & 5 \\
\hline
\end{tabular}




\subsection{Reliability Analysis}

The most suitable index for the reliability test of the questionnaire is Cronbach's $\alpha$ coefficient. When the coefficient value is greater than 0.7 , it can be considered that the questionnaire as a whole has a high consistency. The results of table 2 show that the Cronbach's $\alpha$ coefficients of 4 variables are all over 0.9 , indicating that the reliability of each variables is good and the questionnaire is credible.

Table 2. Reliability of each variable

\begin{tabular}{ccc}
\hline Dimension & Cronbach's $\alpha$ & Item number \\
\hline Job Competence & 0.954 & 9 \\
Job Insecurity & 0.941 & 6 \\
Perceived Organizational Support & 0.921 & 5 \\
Job Well-being & 0.983 & 28 \\
\hline
\end{tabular}

\subsection{Correlation Analysis}

From the statistical results in Table 3, the Pearson correlation coefficient between job competency and job insecurity is 0.575 , and the corresponding $\mathrm{P}$ value is less than 0.01 , indicating that there is a significant positive relationship between job competency and job insecurity at $1 \%$ significance level. The Pearson correlation coefficient between job insecurity and job well-being is -0.639 , and the corresponding $\mathrm{P}$ value is less than 0.01 , indicating that there is a significant negative relationship between job insecurity and job well-being at $1 \%$ significance level. Similarly, perceived organizational support organizational is positively correlated with job well-being, and job competency is positively correlated with job well-being. The results of correlation analysis can verify hypothesis $\mathrm{H} 1, \mathrm{H} 3$ and deny $\mathrm{H} 2$.

Table 3. Pearson correlation analysis of each dimension

\begin{tabular}{lcccc}
\hline Dimension & 1 & 2 & 3 & 4 \\
\hline 1. Job Competence & 1 & & & \\
2. Job Insecurity & $0.575^{* *}$ & 1 & & \\
3. Perceived Organizational Support & $0.678^{* *}$ & $0.594^{* *}$ & 1 & \\
4. Job Well-being & $0.727^{* *}$ & $-0.639^{* *}$ & $0.749^{* *}$ & 1 \\
\hline
\end{tabular}

Note. $* *$ At a confidence level of 0.01 , the significance test of the correlation is passed.

\subsection{Regression Analysis}

In the research, two-step regression method was used to test the adjustment effect of organizational support. The first step is to take job well-being as the dependent variable and job insecurity and perceived organizational support as the independent variables to conduct a multiple linear regression analysis. The second step took job well-being as the dependent variable and job insecurity, Perceived organizational support and job insecurity multiplied by Perceived organizational support as the independent variables to conduct multiple linear regression analysis. According to the statistical results in table 4, the regression results of the first step are shown in model 1, $R^{2}$ is 0.692 , the regression coefficient of job insecurity is- 1.058 , the T value is -12.468 , the $P$ value is 0.000 , and the $\mathrm{P}$ value is less than 0.01 . It indicates that at the significance level of $1 \%$, the coefficient of job insecurity has a very significant statistical significance, that is, there is a very significant negative relationship between job insecurity and job well-being. This also verifies hypothesis $\mathrm{H} 3$.

Similar to perceived organizational support, $\mathrm{R}^{2}$ is 0.692 , the regression coefficient of perceived organizational support is 1.841 , the $\mathrm{T}$ value is 21.710 , the $\mathrm{P}$ value is 0.000 , and the $\mathrm{P}$ value is less than 0.01 . It can be seen that there is a significant positive relationship between organizational support and job well-being. The regression results of the second step are shown in model $2, \mathrm{R}^{2}$ is 0.792 , that is, $\mathrm{R}^{2}$ of model 2 is greater than model 1 , and the interaction between job insecurity and organizational support (job insecurity multiplied by perceived organizational support) is very significant, indicating that organizational support has a significant regulatory 
effect and a negative regulatory effect. This also verifies hypothesis H4.

Table 4. Verification of moderating effects

\begin{tabular}{|c|c|c|c|c|}
\hline \multicolumn{3}{|l|}{ The Dependent Variable } & \multicolumn{2}{|c|}{ Job Well-Being } \\
\hline Variables & \multicolumn{2}{|c|}{ Model 1} & \multicolumn{2}{|c|}{ Model 2} \\
\hline & $\beta$ & $\mathrm{t}$ & $\beta$ & $\mathrm{t}$ \\
\hline Job Insecurity & -1.058 & $-12.468 * * *$ & -0.669 & $-4.130 * * *$ \\
\hline $\begin{array}{l}\text { Perceived } \\
\text { Support }\end{array}$ & 1.841 & $21.710 * * *$ & 1.643 & $14.654 * * *$ \\
\hline $\begin{array}{l}\text { Job Insecurity } * \text { Perceived } \\
\text { Organizational Support }\end{array}$ & & & -0.839 & $-7.478 * * *$ \\
\hline $\mathrm{F}$ & & & & \\
\hline $\mathrm{R}^{2}$ & & & & \\
\hline $\operatorname{adj}-R^{2}$ & & & & \\
\hline Overall model $\mathrm{P}$ value & & & & \\
\hline
\end{tabular}

Note. ${ }^{* * *}$ means $\mathrm{p}<0.01 ; \beta$ : regression coefficient.

\subsection{Structural Equation Model (SEM) Analysis}

\subsubsection{Structural Equation Models}

According to the statistical results in Table 5, the fitting indexes of the model are as follows: Chi-square DOF ratio is 1.508 , less than 3.And GFI is 0.938 , AGFI is 0.946 , NFI is 0.916 , IFI is 0.908 , and CFI is 0.907 .The fitting indexes of the model are all greater than 0.90 , indicating that the model fitting is ideal. SRMR is 0.062 , RMSEA is 0.075 , less than 0.08 , indicates a good model fitness.

Table 5. Fitting indicators of structural equation models

\begin{tabular}{llllllll}
\hline$\chi^{2} / \mathrm{df}$ & GFI & AGFI & NFI & IFI & CFI & SRMR & RMSEA \\
\hline 1.508 & 0.938 & 0.946 & 0.916 & 0.908 & 0.907 & 0.062 & 0.075 \\
\hline
\end{tabular}

\subsubsection{Path Analysis and Mediation Analysis}

From the results of the path coefficients of the structural equations in Table 6, the normalized path coefficient of job insecurity <---job competence is 0.821 , the non-standardized path coefficient is 0.384 , the standard error is 0.066 , the $T$ value is 5.812, and the $P$ value is less than $0.001\left(^{* * *}\right)$, indicating that the path of job competency to job insecurity is significant, and that job competency and job insecurity exhibit a significant positive relationship, which deny hypothesis H2. Similar paths show that job insecurity and job well-being have a significant negative relationship which verifies $\mathrm{H} 3$.

The standardized path coefficient of job well-being<--job competence is -0.096 , the non-standardized path coefficient is -0.085 , the standard error is 0.063 , the T value is -1.338 , and the $P$ value is 0.181 , which indicate that the path from job competence to job well-being is not significant. So it is a complete mediating effect.

Job insecurity plays a significant and complete mediating role in the relationship between job competency and job well-being, the Median effect value is $0.821 *(-0.409)=-0.336$, which verifies H5. 
Table 6. Path analysis results

\begin{tabular}{lccccc}
\hline Path & $\begin{array}{l}\text { Standardization } \\
\text { coefficient }\end{array}$ & $\begin{array}{l}\text { Unstandardized } \\
\text { coefficient }\end{array}$ & $\begin{array}{l}\text { Standard } \\
\text { error }\end{array}$ & $t$ & $p$ \\
\hline Job Insecurity <---Job competency & 0.821 & 0.384 & 0.066 & 5.812 & $* * *$ \\
Job well-being <---Job competency & -0.096 & -0.085 & 0.063 & -1.338 & 0.181 \\
Job well-being<---Job Insecurity & -0.409 & -0.77 & 0.164 & -4.706 & $* * *$ \\
$\begin{array}{l}\text { Job well-being<-- Perceived } \\
\text { Organizational Support }\end{array}$ & 0.893 & 0.645 & 0.066 & 9.799 & $* * *$ \\
\hline
\end{tabular}

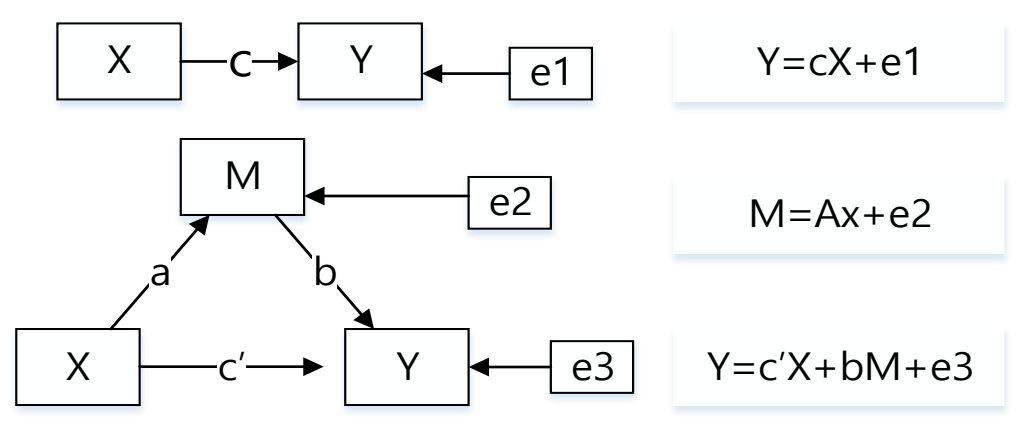

Figure 2. Schematic Diagram of Mediation Variables

\subsection{Hypothesis Verification Results}

Based on the above data analysis results, the validation results of the hypothesis in this study are summarized as shown in Table 7.

Table 7. Hypothesis verification results of this study

\begin{tabular}{cc}
\hline Research hypothesis & Test Results \\
\hline H1 & Supported \\
H2 & Not Supported \\
H3 & Supported \\
H4 & Supported \\
H5 & Supported \\
\hline
\end{tabular}

\section{Conclusions}

This paper takes the relationship among job competency, job insecurity, perceived organizational support and job well-being of service industry employees as the main line of study. Through sampling questionnaire survey data, this paper discusses the influence of job competency on job well-being, and analyzes how job competency influences job well-being through the mediating effect of job insecurity and the moderating effect of perceived organizational support. In this study, the following conclusions were obtained:

Job competency will positively affect their job insecurity, and the stronger job competency, the higher their job insecurity. The stronger the service industry employees' job competence, as a subjective feeling, the higher the degree of job insecurity they feel, which is different from the research results of some scholars, but consistent with the research of Atkinson (1984).

Job insecurity has a significant negative effect on job well-being. The higher the degree of job insecurity, the lower the sense of job well-being. The job competency of service employees will influence their job well-being 
through the intermediary effect of job insecurity.

Perceived organizational support moderates the relationship between job insecurity and job well-being. With the increase of perceived organizational support, the negative influence of job insecurity on job well-being decreased.

This study further enriches the research on job competency and job well-being, reveals the effect of job competency on job well-being, and verifies the important role of job insecurity and perceived organizational support. It provides new ideas for the service industry to strengthen care and support for employees to reduce job insecurity, improve employee happiness and motivate employees.

\section{References}

Abbott, R. A., Ploubidis, G. B., \& Huppert, F. A. (2006). Psychometric evaluation and predictive validity of ryff's psychological well-being items in a UK birth cohort sample of women. Health and Quality of Life Outcomes, 4(1), 76. https://doi.org/10.1186/1477-7525-4-76

Abraído-Lanza, A. F. (1997). Latinas with arthritis: effects of illness, role identity, and competence on psychological well-being. American Journal of Community Psychology, 25(5), 601-627. https://doi.org/10.1023/A:1024682800238

Akkermans, J., Schaufeli, W. B., Brenninkmeijer, V., \& Blonk, R. W. B. (2013). The role of career competencies in the job demands - resources model. Journal of Vocational Behavior, 83(3), 356-366. https://doi.org/10.1016/j.jvb.2013.06.011

Atkinson, J. M. (1984). Structures of social action: studies in conversation analysis. Aphasiology, 1(4), 243-249. https://doi.org/10.1080/026870399402073

Colakoglu, S. N. (2011). The impact of career boundarylessness on subjective career success: the role of career competencies, career autonomy, and career insecurity. Journal of Vocational Behavior, 79(1), 47-59. https://doi.org/10.1016/j.jvb.2010.09.011

Cuyper, N. D. (2014). Perceived employability and performance: moderation by felt job insecurity. Personnel Review, 43(4), 536-552. https://doi.org/10.1108/PR-03-2013-0050

Eisenberger, R. (1986). Perceived organizational support. Journal of Applied Psychology, 71, 500-507. https://doi.org/10.1037/0021-9010.71.3.500

Elst, T. V. (2014). On the reciprocal relationship between job insecurity and employee well-being: Mediation by perceived control? Journal of Occupational \& Organizational Psychology, 87(4), 671-693. https://doi.org/10.1111/joop.12068

Elst, T. V., \& Cuyper, N. D. (2011). The role of perceived control in the relationship between job insecurity and psychosocial outcomes: moderator or mediator? Stress \& Health, 27(3), 215-217. https://doi.org/10.1002/smi.1371

Emberland, J. S., \& Rundmo, T. (2010). Implications of job insecurity perceptions and job insecurity responses for psychological well-being, turnover intentions and reported risk behavior. Safety Science, 48(4), 452-459. https://doi.org/10.1016/j.ssci.2009.12.002

Faris, A. (2018). Job insecurity, organizational commitment, financial responsibility, and turnover intention, a test of three way interaction. International Business Research, 11(6), 213-225. https://doi.org/10.5539/ibr.v11n6p213

Ferrie, J. E., Shipley, M. J., Marmot, M. G., Stansfeld, S., \& Smith, G. D. (1998). The health effects of major organizational change and job insecurity. Social Science \& Medicine, 46(2), 243-254. https://doi.org/10.1016/S0277-9536(97)00158-5

Fugate, M. (2004). Employability: a psycho-social construct, its dimensions, and applications. Journal of Vocational Behavior, 65(1), 14-38. https://doi.org/10.1016/j.jvb.2003.10.005

Gorsuch, R. L. (1983). Moral obligation and attitudes: their relation to behavioral intentions. Journal of Personality and Social Psychology, 44(5), 1025-1028. https://doi.org/10.1037/0022-3514.44.5.1025

Greenhalgh, L., \& Rosenblatt, Z. (1984). Job insecurity: toward conceptual clarity. Academy of Management Review, 9(3), 438-448. https://doi.org/10.5465/amr.1984.4279673 
Griep, Y. (2016). The effects of unemployment and perceived job insecurity: a comparison of their association with psychological and somatic complaints, self-rated health and life satisfaction. International Archives of Occupational and Environmental Health, 89(1), 147-162. https://doi.org/10.1007/s00420-015-1059-5

Hellgren, J., Sverke, M., \& Isaksson, K. (1999). A two-dimensional approach to job insecurity: consequences for employee attitudes and well-being. European Journal of Work \& Organizational Psychology, 8(2), 179-195. https://doi.org/10.1080/135943299398311

Hellgren, M. S. (2010). A two-dimensional approach to job insecurity: consequences for employee attitudes and well-being. European Journal of Work \& Organizational Psychology, 8(2), 179-195. https://doi.org/10.1080/135943299398311

Kuijpers, M. (2006). Career competencies for the modern career. Journal of Career Development, 32(4), 303-319. https://doi.org/10.1177/0894845305283006

Kurtessis, J. N., \& Eisenberger, R. (2015). Perceived organizational support: a meta-analytic evaluation of organizational support theory. Journal of Management, 43(6), 1854-1884. https://doi.org/10.1177/0149206315575554

Maria, C. M., Byron, G., \& Adams, L. S. (2019). Perceived Organizational Support for the Use of Employees' Strengths and Employee Well-Being: A Cross-Country Comparison. Journal of Happiness Studies, 20(6), 1825-1841. https://doi.org/10.1007/s10902-018-0026-8

McClelland, D. C. (1973). Testing for competence rather than for intelligence. American Psychologist, 28(1), 1-14. https://doi.org/10.1037/h0034092

Meneghel, I. (2016). Feeling good makes us stronger: how team resilience mediates the effect of positive emotions on team performance. Journal of Happiness Studies, 17(1), 239-255.

https://doi.org/10.1007/s10902-014-9592-6

Menéndez, E. S., Llosa, J. A., \& Agulló, T. E. (2019). Job Insecurity and Mental Health: The Moderating Role of Coping Strategies from a Gender Perspective. Frontiers in psychology, 10(10), 286. https://doi.org/10.3389/fpsyg.2019.00286

Panaccio, A., \& Vandenberghe, C. (2009). Perceived organizational support, organizational commitment and psychological well-being: a longitudinal study. Journal of Vocational Behavior, 75(2), 224-236. https://doi.org/10.1016/j.jvb.2009.06.002

Reichert, A. R. (2015). Self-perceived job insecurity and the demand for medical rehabilitation: does fear of unemployment reduce health care utilization? Health Economics, 24(1), 8-25. https://doi.org/10.1002/hec.2995

Rhoades, L. (2002). Perceived organizational support: a review of the literature. Journal of Applied Psychology, 87(4), 698-714. https://doi.org/10.1037/0021-9010.87.4.698

Tomietto, M. P., Eleonora, S. R., \& Maricchio, R. C. (2019). Work engagement and perceived work ability: An evidence-based model to enhance nurses' well-being. Journal of advanced nursing, 75(9), 1933-1942. https://doi.org/10.1111/jan.13981

Wang, G., Fan, Y., \& Huang, X. (2018). Effects of Government Support, Organizational Support and Competency on Occupational Well-being among Kindergarten Teachers: Mediating Effect of Occupational Identity. Studies of Psychology and Behavior, 16(06), 83-91.

Wen, J., \& Hou, P. P. (2018). Emotion Intelligence and Job Satisfaction of Hotel Frontline Staff: A Study Based on the Dual-stage Moderating Role of Perceived Organizational Support. Nankai Business Review, 21(1), 146-158.

Witte, H. D. (2016). Review of 30 years of longitudinal studies on the association between job insecurity and health and well-being: is there causal evidence? Australian Psychologist, 5l(1), 18-31. https://doi.org/10.1111/ap.12176

Yeves, J., Bargsted, M., \& Corte, L. (2019). Age and Perceived Employability as Moderators of Job Insecurity and Job Satisfaction: A Moderated Moderation Model. Frontiers in psychology, 10(10), 301-320. https://doi.org/10.3389/fpsyg.2019.00799 
Zhu, Y. Y. (2014). Research on the relationship among marketing personnel competence, organizational support and work well-being: based on the perspective of manufacturing servitization. Industrial Engineering and Management, 19(6), 124-132.

\section{Copyrights}

Copyright for this article is retained by the author(s), with first publication rights granted to the journal.

This is an open-access article distributed under the terms and conditions of the Creative Commons Attribution license (http://creativecommons.org/licenses/by/4.0/). 